\title{
Enhancing Student Retention in Undergraduate Engineering Programs - A Case Study
}

Dr. Ahmed Imran, Ajman Univeristy of Science \& Technology, UAE

Dr. Imran's fields of interest include Engineering Education and Biomedical Engineering.

Dr. Mohamed Nasor M. Kalil

Prof. Fahar G. M. Hayati, Ajman University of Science \& Technology

Professor Fahar Hayati received his B.Eng. degree with honors from Sheffield University in Electronic Engineering in 1966 and the Ph.D. degree from Edinburgh University, Scotland in 1971. Since 1969 he has been extensively involved in the engineering profession and engineering educatuion. His main interest presently is in the area of renewable energy and also in engineering education. Since July, 2000 he has been the Dean of the College of Engineering at Ajman University of Science \& Technology (AUST) in the UAE. 


\title{
Enhancing Student Retention in Undergraduate Engineering Programs - A Case Study
}

\begin{abstract}
In this case study, statistical data was used from three accredited undergraduate engineering programs to analyze and compare two distinct groups of students for various patterns related to program enrollment, retention and attrition. Group A (GA) students were admitted in the years 2000-2005. Group B (GB) students were admitted in the years 2006-2011. The two groups differed in terms of their program-related admission and completion requirements, curriculum design and curriculum contents. Cumulative data until the first semester of the academic year 2012-13 was analyzed.
\end{abstract}

The total intake for GA was $16 \%$ more than that for GB. The student retention was $48 \%$ for GA and $73 \%$ for GB. This is a significant improvement in the retention of students for GB over GA. Further, from those students who aborted their programs, 53\% of the total attrition for GA and $71 \%$ for GB occurred in the first year of admission.

These patterns showed striking similarities when analyzed separately for the sub-group of women students only, or when analyzed for the sub-groups of students considered for each program separately.

The analysis suggests that the retention of undergraduate engineering students could be influenced by admission requirements, program completion requirements and curriculum design and contents. Further, first year students require more attention.

\section{Introduction}

Student retention in universities and, in particular, undergraduate engineering degree programs has been an issue of concern globally ${ }^{(2,3,7,13,17-19)}$. Students' changing academic interests or financial constraints might be possible contributors to attrition. Further, poor or inconsistent performance may also affect students' motivation to continue in a particular program. Students' persistence in engineering programs has been analyzed in relation to their performance in specific courses like mathematics ${ }^{(5,11)}$. Although, several studies have analyzed students' performance in engineering ${ }^{(1,4-6,8-12,14-16)}$, there is a lack of systematic studies to understand the factors that might influence students' retention or reduce attrition from engineering programs.

The purpose of the present case study is to analyze various patterns related to retention and attrition of students in engineering programs in two groups of students before and after introducing various program related changes in order to enhance student retention in their respective programs. 


\section{Methods}

In this case study, statistical data was used from three accredited undergraduate engineering programs (in Electronics, Communication and Biomedical Engineering) to analyze and compare two groups of students for various patterns related to the following:

i. Program enrollment (or intake) (A),

ii. Student retention in the programs (B)

iii. Student attrition from the programs (C).

iv. Student attrition in the first year of the program (D).

v. For the purpose of gender analysis, cumulative data for the women students was also analyzed.

Students in GA were admitted during six-year period 2000-2005. Students in GB were admitted during six-year period 2006-2011.

The difference between the two groups was that starting from the academic year 2006-07 various changes were introduced in the programs related to admission and program completion requirements as well as related to the curriculum design and contents. The changes are described later in the 'Discussion' section.

Cumulative data until the first semester of the academic year 2012-13 was analyzed.

\section{Results}

Table 1 gives various patterns (from A to D) for students in the group GA.

Table 2 gives the same patterns for students in the group GB.

In column A, the total intake for the academic year 2000-01 was reduced to 100, which was used as the base-year to normalize the intake for all other academic years in both the tables.

In the two tables, '\% Retention' corresponds to the students who either completed or are continuing their studies in the same program with which they started. Also, '\% Attrition' corresponds to the students who aborted or did not continue in their program with which they started.

Table 1: Observed patterns for the students in group GA.

\begin{tabular}{|c|c|c|c|c|}
\hline $\begin{array}{c}\text { Academic } \\
\text { year }\end{array}$ & $\begin{array}{c}\text { A } \\
\text { Total intake } \\
\text { (normalized) }\end{array}$ & $\begin{array}{c}\text { B } \\
\text { \% Retention } \\
\text { (as a percentage of A) }\end{array}$ & $\begin{array}{c}\text { C } \\
\text { \% Attrition } \\
\text { (C = 100-B) }\end{array}$ & $\begin{array}{c}\text { D } \\
\text { (as year Attrition (\%) }\end{array}$ \\
\hline $2000-01$ & 100 & 37 & 63 & 48 \\
\hline $2001-02$ & 152 & 42 & 58 & 58 \\
\hline $2002-03$ & 128 & 46 & 54 & 59 \\
\hline $2003-04$ & 140 & 49 & 51 & 50 \\
\hline $2004-05$ & 155 & 51 & 49 & 38 \\
\hline $2005-06$ & 155 & 60 & 40 & 63 \\
\hline
\end{tabular}


Table 2: Observed patterns for the students in group GB.

\begin{tabular}{|c|c|c|c|c|}
\hline $\begin{array}{c}\text { Academic } \\
\text { year }\end{array}$ & $\begin{array}{c}\text { A } \\
\text { Total intake } \\
\text { (normalized) }\end{array}$ & $\begin{array}{c}\text { B } \\
\text { Retention (\%) } \\
\text { (as a percentage of A) }\end{array}$ & $\begin{array}{c}\text { C } \\
\text { Attrition (\%) } \\
\text { (C = 100-B) }\end{array}$ & $\begin{array}{c}\text { D } \\
\text { 1st year Attrition (\%) } \\
\text { (as a percentage of C) }\end{array}$ \\
\hline $2006-07$ & 93 & 68 & 32 & 76 \\
\hline $2007-08$ & 99 & 64 & 36 & 66 \\
\hline $2008-09$ & 126 & 61 & 39 & 55 \\
\hline $2009-10$ & 128 & 69 & 31 & 75 \\
\hline $2010-11$ & 127 & 76 & 24 & 84 \\
\hline $2011-12$ & 145 & 92 & 8 & 95 \\
\hline
\end{tabular}

The data from columns $\mathrm{D}$ of the two samples was tested statistically using t-test for significance level $(\alpha=0.05)$ with the result of t-statistic $=3.31$, while $t$-critical (one tail) was 1.83 . The null hypothesis that "the two means were equal" was rejected.

Overall, the six-year cumulative data for each group is summarized as follows:

i. Compared to GB, the total intake was $16 \%$ higher for GA.

ii. The student retention was $48 \%$ for GA and $73 \%$ for GB.

iii. From those students who aborted their programs, $53 \%$ of attrition for GA and $71 \%$ of attrition for GB occurred in the first year of admission.

iv. Women in each group, by coincidence, were $30 \%$ of the total respective intake.

v. The student retention among women was 55\% for GA and 79\% for GB.

vi. From the women students who aborted their programs, 56\% of attrition for GA and 73\% of attrition for GB occurred in the first year of admission.

\section{Discussion}

During the period for GA, significant attrition of students from their respective programs was a cause of concern for the College of Engineering. To understand the causes and to find remedies, systematic and well planned actions were taken which included obtaining and analyzing feedback from various stakeholders including the following:
a) Employers of the program graduates
b) Program alumni
c) Senior level students
d) Program faculty members

In addition, comparative studies involving similar programs of other reputed universities from different countries were also conducted to analyze the curriculum design and contents.

Further, expert advice was sought from senior evaluators of engineering programs including those with ABET experience. 
Based on recommendations of several working groups and committees, the following major changes were introduced in the programs from the academic year 2006-2007:

1. The program admission criterion was enhanced by introducing requirement of a minimum score in standardized English language test like TOEFL (Test Of English as a Foreign Language). Previously, non-standardized tests for English were conducted.

2. The program completion requirement of 165 credit hours was reduced for each program by at least 23 credit hours.

3. The curriculum was redesigned to ensure that the students' transition from the junior to the senior level courses was smooth in terms of knowledge, skills and various relevant competencies. This involved ensuring appropriate prerequisites and sequencing for the courses in the study plan.

4. The program contents were enhanced to ensure that the students' interest and motivation in engineering were developed and sustained from the early stages of the programs. This involved adding topics, courses and activities in the early years of study so that the students could learn about their field of study as well as interact with the specialized faculty members from their respective programs.

In addition, necessary resources to support implementation of the programs like laboratories, libraries, computers, hardware and software were also strengthened and updated.

After more than seven years of introducing such changes, this comparative study was conducted. The study shows that, though cumulative intake for the group GB is somewhat less than that for GA, there is a significant improvement in student retention.

Moreover, another significant improvement is observed in the form of an early attrition of students, with $71 \%$ of the total attrition in GB as compared to $53 \%$ of the total attrition in GA, took place within the first year of admission. This may be considered as a positive development as the students might have been in a better position to take an early decision about continuing or aborting their respective program.

Although, the women in each group formed about $30 \%$ of the respective total intake, the six-year cumulative data showed patterns very similar to those of the total groups.

Further, these patterns of student retention and of the first year attrition were strikingly similar for each of the three programs when analyzed individually.

It may be worth mentioning that in this study, no control factor like students' performance, GPA or their preparation level was taken into account. 


\section{Conclusions}

The analysis suggests that the retention of undergraduate engineering students could be influenced by admission requirements, program completion requirements and curriculum design and contents. Further, first year students require more attention.

\section{Bibliography}

1. Ali, A., \& Ali, U. (2010). Predictability of engineering students' performance at the University of Engineering and Technology, Peshawar from admission test conducted by Educational Testing and Evaluation Agency (ETEA), NWFP, Pakistan. Procedia Social and Behavioral Sciences, 2, 976-982.

2. Andrew, S., Salamonson, Y., Weaver, R., Smith, A., O’Reilly, R., \& Taylor, C. (2008). Hate the course or hate to go: Semester differences in first year nursing attrition, Nurse Education Today, 28(7), 865-872.

3. Baker, J.G. (1998). Gender, race and Ph.D. completion in natural science and engineering, Economics of Education Review, 17(2), 179-188.

4. Cohen, L. (1946). Predicting academic success in an engineering college and suggestions for an objective evaluation of high-school marks. Journal of Educational Psychology, 37(6), 381-384.

5. DeJong, B., \& Langenderfer, J. (2012). Enrollment and persistence of first-year students in a newly accredited engineering program. ASEE 2012 Annual Conference (http://www.asee.org/search/proceedings) (Last accessed, March 2013).

6. Fechheimer, M., Webber, K., \& Kleiber, P. B. (2011). How well do undergraduate research programs promote engagement and success of students? Life Sciences Education (CBE), 10, 156-163.

7. Hayden, A. (2010). Student Attrition from Higher Education Institutions, In: International Encyclopedia of Education (Third Edition), Elsevier, Oxford, 467-472.

8. Howe, T., Li, V., \& Julaihi, N.H. (2010). The relationships between students' underachievement in mathematics courses and influencing factors. Procedia Social and Behavioral Sciences, 8, 134-141.

9. Imran, A., Nasor, M., \& Hayati, F. (2012). Factors influencing attrition in a biomedical engineering program. International Forum on Engineering Education (IFEE-2012), K.L., Malaysia, 20-22 Nov. 2012.

10. Imran, A., Nasor, M., \& Hayati, F. (2011 (a)). Analysis of students' school results and performance in engineering programs - a case study. International Journal on New Trends in Education and Their Implications, $2(4), 38-43$.

11. Imran, A., Nasor, M., \& Hayati, F. (2011 (b)). Influence of mathematics and science courses on students' performance in engineering programs. Proc. 2nd Int. Conf. on New Trends in Education and Their Implications. Turkey, pp. 548-551.

12. Imran, A., Nasor, M., \& Hayati, F. (2010). Gender-based statistical analysis of students in engineering programs over ten years. Proc. 5th International Forum on Engineering Education (IFEE) - Engineering Education in the 21 st Century - Quality, Globalization and Local Relevance. UAE; 23-25 Nov 2010.

13. Lassibille, G., \& Gómez M.L.N. (2010). How long does it take to earn a higher education degree in Spain?, Procedia - Social and Behavioral Sciences, 2(2), 3519-3523.

14. Madsen, J.N., \& Ingram, P. (2010). Mathematics tutoring and student success. Procedia Social and Behavioral Sciences, 8, 207-212.

15. Madsen, J.N., Bales, R.A., \& Hynds, D.L. (2010). Role of scholarships in improving success rates of undergraduate Science, Technology, Engineering and Mathematics (STEM) majors. Procedia Social and Behavioral Sciences, 8, 458-464.

16. Nasor, M., Imran, A., \& Hayati, F. (2011). Achieving enhanced performance in undergraduate biomedical engineering program. ICIE (Germany) conference on 'Excellence in Education 2011: Giftedness-CreativityDevelopment'. Turkey, pp. 93.

17. Ragusa, G., \& Lee, C.T. (2012). The impact of focused degree projects in chemical engineering education on students' research performance, retention, and efficacy, Education for Chemical Engineers, ISSN 1749-7728, 10.1016/j.ece.2012.03.001. 
18. Santiago, L. \& Hensel, R. (2012). Engineering attrition and university retention. ASEE 2012 Annual Conference (http://www.asee.org/search/proceedings) (Last accessed, March 2013).

19. White, J.L., Altschuld, J.W., \& Lee, Y.F. (2008). Evaluating minority retention programs: Problems encountered and lessons learned from the Ohio science and engineering alliance, Evaluation and Program Planning, 31(3), 277-283. 